05,04

\title{
Исследование особенностей состава, магнитной и кристаллической структуры гексаферрита бария $\mathrm{BaFe}_{12-x} \mathrm{Ti}_{x} \mathrm{O}_{19}$
}

\author{
() В.В. Коровушкин ${ }^{1}$, А.В. Труханов ${ }^{1,2, \uparrow, ~ В . Г . ~ К о с т и ш и н ~}{ }^{1}$, И.М. Исаев ${ }^{1}$, И.В. Щетинин ${ }^{1}$, Н.М. Дуров ${ }^{1}$, \\ А.Ю. Миронович ${ }^{1}$, И.О. Минкова ${ }^{1}$, К.А. Астапович ${ }^{2}$ \\ ${ }^{1}$ Национальный исследовательский технологический университет „МИСиС“, \\ Москва, Россия \\ 2 ГО НПЦ НАН Беларуси по материаловедению, \\ Минск, Беларусь \\ I E-mail: truhanov86@mail.ru
}

Поступила в Редакцию 31 октября 2019 г.

В окончательной редакции 17 декабря 2019 г.

Принята к публикации 24 декабря 2019 г.

\begin{abstract}
Представлены результаты исследований особенностей состава, кристаллической и магнитной структуры Тi-замещенного гексаферрита бария $\mathrm{BaFe}_{12-x} \mathrm{Ti}_{x} \mathrm{O}_{19} \quad(0.25 \leq x \leq 1.5)$ методами мессбауэровской спектроскопии, вибрационной магнитометрии, рентгенографиии и синхронного термического анализа. При частичном замещении ионов $\mathrm{Fe}^{3+}$ ионами $\mathrm{Ti}^{4+}$ установлено наличие ограниченного гетеровалентного изоморфизма, реализуемого по схеме $2 \mathrm{Fe}^{3+} \rightarrow \mathrm{Ti}^{4+}+\mathrm{Fe}^{2+}$ с сохранением зарядового баланса. Методом мессбауэровской спектроскопии установлено увеличение электронной плотности $3 d$-электронов и наличие $\mathrm{Fe}^{2+}$ в образцах $\mathrm{BaFe}_{12-x} \mathrm{Ti}_{x} \mathrm{O}_{19} \mathrm{c} x=1.5$. Установлен предел гетеровалентного изоморфного замещения, находящийся в диапазоне $0.75<x<1.0$. С помощью мессбауэровской спектроскопии и рентгенографии показано образование титаносодержащих фаз при $x=1,0$, содержание которых увеличивается по мере возрастания степени замещения. Представлены сведения о преимущественном характере распределения ионов-заместителей $\left(\mathrm{Ti}^{4+}\right)$ в структуре гексаферрита бария в позициях $12 k$ и $2 b$.
\end{abstract}

Ключевые слова: гексаферриты, гетеровалентное замещение, титан, мессбауэровская спектроскопия, магнитные свойства, рентгенография, синхронный термический анализ.

DOI: 10.21883/FTT.2020.05.49250.622

\section{1. Введение}

Магнитные свойства гексаферритов бария зависят как от вида изоморфной примеси, так и ее количества в структуре, что создает возможность не только изучать их свойства, но и синтезировать образцы с заданными характеристиками для практического использования.

Гексаферриты $M$-типа и их твердые растворы имеют кристаллическую структуру, изоморфную природному минералу — магнетоплюмбиту $\mathrm{PbFe}_{12} \mathrm{O}_{19}$, которая впервые была изучена Адельскольдом [1].

Ионы железа в структуре гексаферрита с такой структурой локализованы в пяти неэквивалентных кристаллографических положениях: $2 a, 2 b, 4 f_{1}, 4 f_{2}$ и $12 k$. Из них $2 a, 4 f_{2}$ и $12 k$ являются октаэдрическими, $4 f_{1}-$ тетраэдрической, а $2 b$ образует бипирамиду. Полиэдры $4 f_{1}$ и $2 a$ расположены в шпинельном блоке $(S), 4 f_{2}$ и $2 b$ в гексагональном $(R)$, а $12 k$ на границе шпинельного и гексагонального блоков $(R S)[2]$.

$\mathrm{B}$ незамещенном гексаферрите $\mathrm{BaFe}_{12} \mathrm{O}_{19}$ выполняется коллинеарная магнитная структура, в которой магнитные моменты позиций $12 k, 2 a$ и $2 b$ направлены в одну сторону, а $4 f_{1}$ и $4 f_{2}$ в другую, антипараллельно [3], что приводит к нескомпенсированому антиферромагнетизму (ферримагнетизму). Ослабление этих взаимодействий за счет замещения ионов $\mathrm{Fe}^{3+}$ обеих групп немагнитными и/или слабомагнитными ионами металла приводит к уменьшению результирующего магнитного момента и может привести к неколлинеарной магнитной структуре [4].

Для контролируемого изменения магнитных и электрических свойств используется принцип изменения химического состава гексаферрита.

В основном большинство исследователей при этом рассматривали изовалентное замещение ионов $\mathrm{Fe}^{3+}$ ионами металлов с близким ионным радиусом и степенью окисления 3+, поскольку при этом зарядовый баланс реализуется довольно легко (сохранение закона электронейтральности) [5,6]. Вхождение двух или несколько различных элементов одной валентности также не вызывало проблем с зарядовым балансом, но усложняет интерпретацию с локализацией их в структуре [7]. Гораздо сложнее обстоит дело с зарядовым балансом, если рассматривать гетеровалентные замещения. Ряд авторов для обеспечения зарядового баланса при синтезе используют замещения ионов $\mathrm{Fe}^{3+}$ парой $\mathrm{Me}^{2+}+\mathrm{Me}^{4+}$. Замещениям $\mathrm{Ti}^{4+}$ совместно с двухвалентными ионами $\mathrm{Mn}^{2+} \cdot \mathrm{Co}^{2+}, \mathrm{Zn}$, $\mathrm{Ni}$ изучались во многих работах. Так в гексаферритах стронция авторы [8] замещают ионы $\mathrm{Fe}^{3+}$ ионами $\mathrm{Mn}^{2+}+\mathrm{Ti}^{4+}$, с общей кристаллохимической формулой $\mathrm{SrFe}_{12-2 x} \mathrm{Mn}_{x}^{2+} \mathrm{Ti}_{x}{ }^{4+} \mathrm{O}_{19}$. Если ионы $\mathrm{Mn}$, как считают 
авторы, локализуются в позиции $4 f_{1}$, то по локализации $\mathrm{Ti}^{4+}$ у исследователей разные мнения. Большое количество работ посвящено изучению гексаферритов барии легированных ионами $\mathrm{Ti}^{4+}$ совместно с $\mathrm{Co}^{2+}$, например работа [9]. Полученные результаты показывают, что замещение ионов $\mathrm{Fe}^{3+}$ ионами $\mathrm{Ti}^{4+}$ совместно с ионами $\mathrm{Co}^{2+}$ не приводят к изменению структуры гексаферрита, зарядовый баланс при этом сохраняется, но намагниченность образцов уменьшается. Авторы считают, что такие материалы могут быть использованы как радиопоглощающие.

Аналогичные результаты, приводящие к уменышению намагниченности при вхождении в структуру пары ионов $\mathrm{Ti}^{4+}$ и $\mathrm{Mg}^{2+}$, приводят авторы работы [10], отмечая при этом увеличение параметра элементарной ячейки с увеличением степени замещения $x$. При замещениях ионов $\mathrm{Fe}^{3+}$ ионами $\mathrm{Ti}^{4+}+\mathrm{Zn}^{2+}$, авторы [11] отмечают большую изоморфную емкость гексаферритов и зависимость намагниченности насыщения от методов и условий их синтеза. Авторы работ [12] проводили эксперименты по введении в решетку трех элементов $\left(\mathrm{Ti}^{4+}, \mathrm{Mn}^{2+}, \mathrm{Cu}^{2+}\right)$ при $x=1,2$ и 3, отмечая, что при $x=2$, согласно данным рентгенографии, гексаферрит еще являлся однофазным. Однако авторы работы [13] при $x=2$ фиксировали появление второй фазы. Авторы отмечают уменьшение намагниченности насыщения и увеличение магнитной проницаемости с ростом $x$. Увеличение количества замещающих ионов до 4-х приводило к неоднозначности результатов. В работе [14] авторы считают, что получили материал с отсутствием агломерации пригодным для использования в высокочастотных магнитных устройствах. В работе [15] уже при $x=0,5$ магнитные характеристики имели сложный характер в результате неоднозначного катионного распределения замещающих элементов в структуре. Следует отметить, что при большом количестве разнообразных замещающих ионов установить локализацию катионов довольно трудно и, кроме того, сложно установить преобладающее влияние какого-либо замещающего иона на свойства гексаферрита.

Поскольку изовалентные замещения ионов $\mathrm{Fe}^{3+}$ одиночными элементами и парой $\mathrm{Me}^{2+}+\mathrm{Me}^{4+}$ изучены достаточно широко, представляет интерес рассмотреть гетеровалентные замещения ионов $\mathrm{Fe}^{3+}$ отдельно ионами $\mathrm{Me}^{2+}$ и $\mathrm{Me}^{4+}$. Немногочисленные источники свидетельствуют, что изоморфная емкость гексаферрита при вхождении титана несколько выше, чем для других элементов, что расширяет возможность использования таких гексаферритов в СВЧ-технике. Учитывая это, нами для исследования был выбран гексаферрит легированный ионами $\mathrm{Ti}^{4+}$.

К ранним исследованиям гексаферритов бария легированных титаном можно отнести работу [16], в которой исследовался природный аналог гексаферрита состава $\mathrm{BaFe}_{10} \mathrm{Ti}_{2} \mathrm{O}_{19}$ найденный в Германии и утвержденный как новый минерал Батиферрит. Были исследованы его состав, физические свойства и структура, которая по данным рентгенографии соответствовала структуре магнетоплюмбита. В работе [17] авторы, исследуя гексаферриты с $x=0.0 ; 0.6 ; 0.8$ и 1.0 методами рентгенографии и магнитометрии отмечают изменение параметров элементарной ячейки и вхождение титана в тетраэдрические позиции $(17 \%)$ и октаэдрические (75\%), что приводит к уменышение остаточной намагниченности и магнитной анизотропии с ростом содержания Тi. При этом они считают, что при малых концентрациях титана намагниченность увеличивается, а с ростом его содержания уменьшается.

Серия гексаферритов бария $M$-типа была синтезирована с частичным замещением $\mathrm{Fe}_{2} \mathrm{O}_{3}$ на $\mathrm{TiO}_{2}$ в работе [18]. Расплав имел состав (mol.\%) $40 \mathrm{BaO}+33 \mathrm{~B}_{2} \mathrm{O}_{3}$ $+(27-x) \mathrm{Fe}_{2} \mathrm{O}_{3}+x \mathrm{TiO}_{2}$ где $x=0.0 ; 3.6 ; 5.4$ и $7.2 \mathrm{~mol} . \%$ $\mathrm{TiO}_{2}$. Замещенные ферриты были изучены с помощью рентгеновской дифракции, мессбауэровской спектроскопии и магнитометрии. Данные рентгенографии показали, что все образцы кроме ферритной фазы имели примесь фазы $\mathrm{BaTi}_{6} \mathrm{O}_{13}$. Мессбауэровские спектры, снятые для составов с $x=0.0 ; 3.6 ; 5.4 \mathrm{~mol} . \% \mathrm{TiO}_{2}$, показали наличие магнитного упорядочения с сильным уширением линий. Кроме того, расширение линий увеличивалось с повышением содержания $\mathrm{TiO}_{2}$. Согласно мессбауэровским параметрам ионы $\mathrm{Ti}^{4+}$ занимают позиции $2 a$ и $12 k$, а при высоком содержании также $2 b$ и $4 f_{2}$, что вызывает уменьшение коэрцитивной силы и намагниченности насыщения.

Монокристаллы Ті-замещенного гексаферрита бария $\mathrm{BaFe}_{12-x} \mathrm{Ti}_{x} \mathrm{O}_{19}$ с $x<1.3$ были изучены в работах $[19,20]$. Распределение Ті по разным кристаллографическим позициям определялось по данным рентгеноструктурного анализа. При низком содержании Ті ( $x$ до 0.8) элементная ячейка расширяется; при дальнейшем увеличении $x$ элементарная ячейка начинает сжиматься. Авторы это связывают с переходом $\mathrm{Fe}^{3+}$ в $\mathrm{Fe}^{2+}$ и образованием вакансий для соблюдения баланса заряда. При этом авторы отмечают монотонное снижение температуры Кюри и намагниченности.

Литературные источники показывают, что среди исследователей нет единого мнения по катионному распределению в структуре гексаферрита и конкретно по локализации титана. Если в одних работах утверждается, что ионы $\mathrm{Ti}^{4+}$ могут входить практически во все позиции кроме $4 f_{1}[18]$, то в других отрицается его вхождение в позицию $2 b$ [17]. Возникают вопросы и по механизму зарядового баланса в гексаферрите при вхождении в решетку ионов $\mathrm{Ti}^{4+}$ и появлении ионов с повышенным изомерным сдвигом до $0.49 \mathrm{~mm} / \mathrm{s}$, отнесенным непосредственно к ионам $\mathrm{Fe}^{2+}[18]$, а также появлению дополнительных фаз в зависимости от концентрации титана.

В связи с этим, целью настоящей работы было изучение корреляции химического и фазового состава и магнитных свойств, как функции преимущественного распределения гетеровалентного иона-заместителя в исследуемых образцах $\mathrm{BaFe}_{12-x} \mathrm{Ti}_{x} \mathrm{O}_{19}$ с $0.25 \leq x \leq 1.5$ при реализации схемы зарядового баланса. 


\section{2. Объекты и методы исследования}

Объектами исследования служили образцы поликристаллических гексаферритов бария $\mathrm{BaFe}_{12-x} \mathrm{Ti}_{x} \mathrm{O}_{19}$, где $x=0.25 ; 0.5 ; 0.75 ; 1.0 ; 1.25$ и 1.5 . Образцы изготовлялись по керамической технологии из оксидов $\mathrm{Fe}_{2} \mathrm{O}_{3}, \mathrm{TiO}_{2}$ и карбоната $\mathrm{BaCO}_{3}$ квалификации „ОСЧ“. Предварительный исходный состав подвергался синтезирующему обжигу на воздухе при $1200^{\circ} \mathrm{C}(6 \mathrm{~h})$, а затем спекался при $1300^{\circ} \mathrm{C}(6 \mathrm{~h})$. После спекания образцы медленно охлаждались в печи $\left(\sim 100^{\circ} / \mathrm{h}\right)[13]$.

Мессбауэровские спектры образцов $\mathrm{BaFe}_{12-x} \mathrm{Ti}_{x} \mathrm{O}_{19}$ снимались на спектрометре Ms-1104 Em с постоянным ускорением, числом точек 512 , источником $\gamma$-излучения $\mathrm{Co}^{57}$ в матрице хрома, при комнатной температуре. Изомерный (химический) сдвиг рассчитывался относительно $\alpha$-Fе. Использовались порошковые пробы крупностью $0.05-0.07 \mathrm{~mm}$ из спеченных ферритов. Математическая обработка спектров проводилась по программе Univem Ms.

Магнитные параметры: удельную намагниченность $\sigma_{s}$, остаточную намагниченность $\sigma_{r}$, коэрцитивную силу $H_{c}$, форму петли гистерезиса измеряли на вибрационном магнитометре VSM 250 в магнитном поле напряженностью $20 \mathrm{kOe}$ при $300 \mathrm{~K}$. Температуру Кюри образцов определяли на установке синхронного термического анализа СТА 449 С в магнитном поле. Фазовый состав образцов определялся с помощью дифрактометра Rigaku Ultima IV c фокусировкой по Брэггу-Брентано на Сu- $K_{\alpha}$ излучении с использованием графитового монохроматора на дифрагированном пучке. Режим сканирования по точкам, диапазон углов $2 \theta: 20-140^{\circ}$, шаг 0.05 . По межплоскостным расстояниям рассчитывались параметры элементарной ячейки гексаферритов.

\section{3. Исследовательская часть}

Мессбауэровские спектры образцов гексаферритов $\mathrm{BaFe}_{12-x} \mathrm{Ti}_{x} \mathrm{O}_{19}$ приведены на рис. 1. По программе Univem Ms все спектры были разложены на составляющие секстеты и дублеты. Модель разложения задавалась из следующих соображений. В замещенных ферритах выделялись секстеты, принадлежащие ионам железа основных пяти позиций, с параметрами незамещенного гексаферрита и визуально определялись положения дополнительных секстетов и дублетов. Наилучший вариант обработки по программе определялся по параметру $\min \chi^{2}$ при сохранении физического смысла мессбауэровских параметров. По уменьшению интегральных интенсивностей пиков секстетов устанавливались позиции в структуре, в которые входят ионы примесей, и какие магнитные связи косвенного магнитного обмена $\mathrm{Fe}-\mathrm{O}-\mathrm{Fe}$ обрываются. При этом учитывалось, что неэквивалентные положения ионов $\mathrm{Fe}$ при вхождении замещающего иона в позиции $2 a, 2 b, 4 f_{1}$ и $4 f_{2}$ могут образовываться в соседних полиэдрах, с которыми рвутся обменные магнитные связи и лишь вхождение иона-примеси в позицию $12 k$ может образовывать неэквивалентные положения $12 k^{\prime}$ за счет сочленения трех октаэдров $12 k$.

В соответствии с приведенными соображениями мессбауэровские спектры образцов с $x=0.25$ и 0.50 были разложены на 6 секстетов, а спектр образца с $x=0.75$ на 7 секстетов. В спектре образца с $x=1.0$; появился дополнительный дублет, а спектры образцов с $x=1.25$ и 1.5 были разложены на 8 секстетов и дублет. Такое разложение обеспечило наилучшие варианты критерия Пирсона $\chi^{2}$. При этом увеличение $x$ сопровождалось не только увеличением числа секстетов в экспериментальных спектрах, но и возрастанием интегральной интенсивности дублетов. Полученные параметры секстетов и дублетов изомерный (химический) сдвиг $\delta(\mathrm{mm} / \mathrm{s})$, квадрупольное расщепление $\Delta(\mathrm{mm} / \mathrm{s})$, магнитное поле на ядрах $\mathrm{Fe}^{57}$, площади компонент спектра $S$ (rel.\%), ширина резонансной линии $\Gamma(\mathrm{mm} / \mathrm{s})$, их соответствие с занимаемыми позициями, а также угол $\theta$ между магнитным моментом образца и вектором $\gamma$-излучения в спектрометре приведены в табл. 1. Для сопоставления в таблице приведены параметры одного из незамещенных гексаферритов бария. Поскольку основной вклад в дополнительные секстеты С6 и С7 вносят неэквивалентные ионы позиции $12 k$, то они обозначены как $12 k^{\prime}$ и $12 k^{\prime \prime}$.

Появление дублета в спектре образца с $x=1$, с одной стороны, свидетельствует о том, что титан прекратил вхождение в структуру гексаферрита $\mathrm{BaFe}_{12-x} \mathrm{Ti}_{x} \mathrm{O}_{19}$, и наступило его насыщение, а с другой, видим распад твердого раствора и образование новых железотитановых фаз. Поскольку в гексаферите с $x=0.75$ дублета еще не наблюдается, а при $x=1$ его интегральная интенсивность существенна, можно считать, что предел ограниченного изоморфизма гексаферрита. $\mathrm{BaFe}_{12-x} \mathrm{Ti}_{x} \mathrm{O}_{19}$ лежит в интервале $0.75<x<1.0$. Кроме того в мессбауэровских спектрах с $x=1.25$ и $x=1.5$ фиксируется фаза антиферромагнитного $\alpha-\mathrm{Fe}_{2} \mathrm{O}_{3}$.

Оценивая мессбауэровские параметры табл. 1, можно отметить вариации изомерного сдвига $\delta$ от ионов $\mathrm{Fe}^{3+}$ 5-ти основных позиций (секстеты 1-5), как для незамещенных, так и замещенных гексаферритов. Сравнения показывают большую величину $\delta$ для ионов $\mathrm{Fe}^{3+}$ октаэдрических позиций $12 k, 4 f_{2}$ и $2 a(\delta=0.33-0.39 \mathrm{~mm} / \mathrm{s})$ по сравнению с тетраэдрической $4 f_{1}$ и бипирамидальной $2 b(\delta=0.23-0.29 \mathrm{~mm} / \mathrm{s})$ в соответствии с [21]. Это объясняется большей ковалентностью связи между ионами железа, за счет меньшего объема полиэдров $4 f_{1}$ и $2 b$. Квадрупольное расщепление $\Delta$ ионов $\mathrm{Fe}$, при этом увеличивается за счет большего отклонения симметрии октаэдров $12 k$ от идеальной. При этом вклад в градиент электрического поля создают только лиганды [22,23]. В связи с этим, можно отметить значительные искажения симметрии полиэдра $2 b(\Delta=2.07-2.23 \mathrm{~mm} / \mathrm{s})$, в то время как для самого симметричного октаэдра $2 a, \Delta-$ изменяется в пределах $0.1-0.18 \mathrm{~mm} / \mathrm{s}$. 

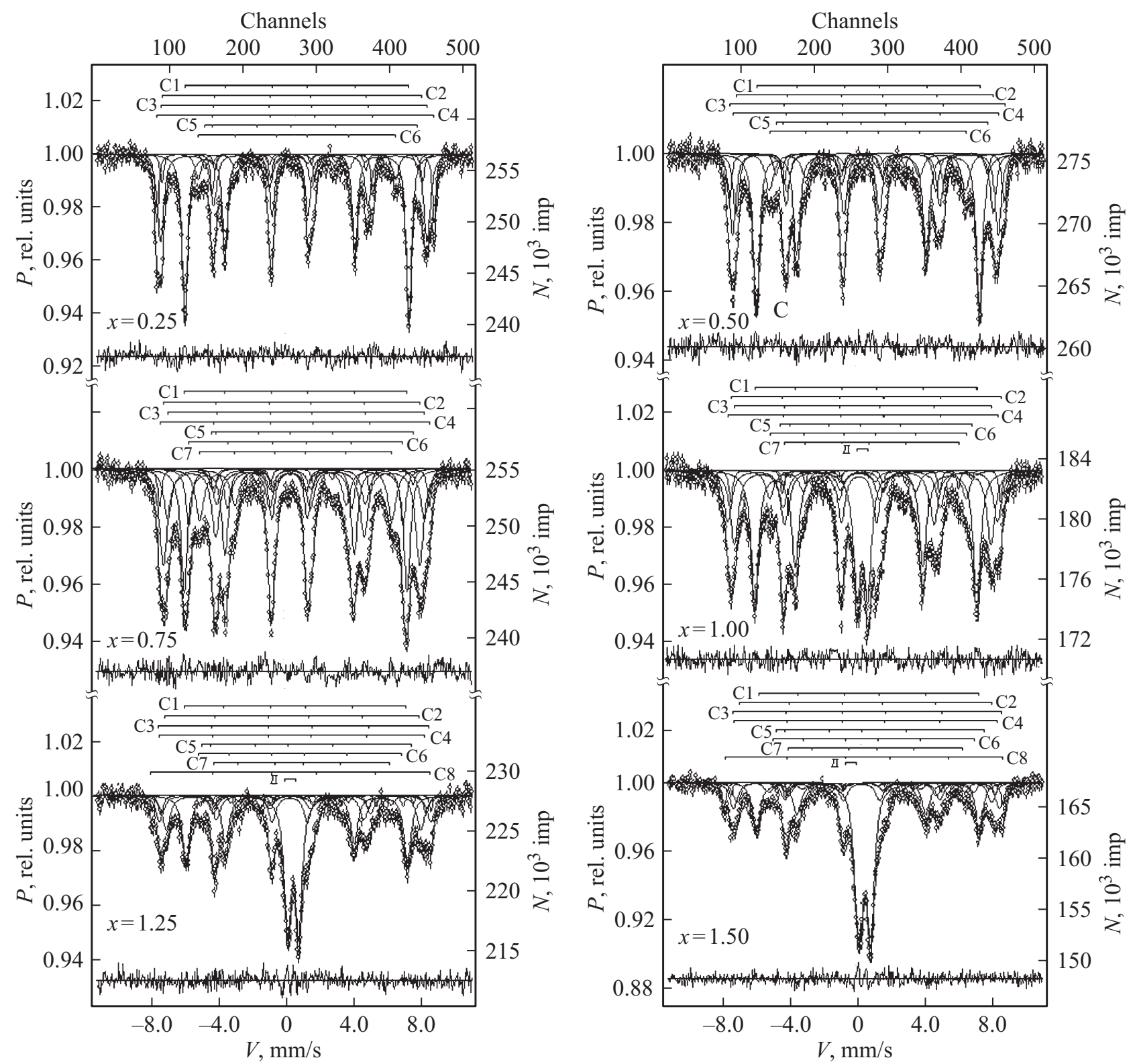

Рис. 1. Мессбауэровские спектры гексагональных ферритов типа $M \mathrm{BaFe}_{12-x} \mathrm{Ti}_{x} \mathrm{O}_{19}(x=0.25 ; 0.5 ; 0.75 ; 1,00 ; 1.25 ; 1.50)$.

Значительное увеличение $\delta$ дополнительных секстетов может быть объяснено, с одной стороны, уменьшением ковалентности связи ионов $\mathrm{Fe}^{3+}$, когда октаэдр $12 k$ отдает ионы железа на образование железо-титановых структур и возникновении при этом катионных вакансий. Это сопровождается увеличением межкатионных расстояний в триаде октаэдров $12 k$, что приводит к увеличению ионной связи. При этом плотность $P$-электронов уменьшается за счет увеличения экранирующего эффекта $d$-электронов, в результате чего изомерный сдвиг увеличивается.

С другой стороны, интерес вызывает схема реализации зарядового баланса в гексаферрите с изоморфным титаном. В классической схеме замещения $2 \mathrm{Fe}^{3+} \rightarrow \mathrm{Ti}^{4+}+\mathrm{Fe}^{2+}$ участвует двухвалентное железо, которое должно регистрироваться с помощью мессбауэровской спектроскопии. Полностью удовлетворяющих состоянию ионов $\mathrm{Fe}^{2+}$, в диапазоне $0.25 \leq x \leq 0.75$ не обнаружено, но небольшое превышение $\delta$ Fe секстетов С6 $\left(12 k^{\prime}\right)$ относительно C1 $(12 k)$ незамещенного гексаферрита имеется. Существенное увеличение $\delta$ наблюдается в дополнительных секстетах при $x=>1.0$. Так в образце с $x=1.0$ в спектре появляется секстет С6 с $\delta=0.44 \mathrm{~mm} / \mathrm{s}$, при $x=1.25$ секстет С6 с $\delta=0.50 \mathrm{~mm} / \mathrm{s}$ и $\mathrm{C} 7$ с $\delta=0.56 \mathrm{~mm} / \mathrm{s}$, а при $x=1.5$ секстет с $\delta=0.63 \mathrm{~mm} / \mathrm{s}$ (табл. 1 ).

Считать, что образовались ионы полностью удовлетворяющих состоянию $\mathrm{Fe}^{2+}$ нельзя, поскольку в работе по систематике валентных и координационных состояний ионов $\mathrm{Fe}^{2+}[21], \delta$ для $\mathrm{Fe}^{2+}$ в окружении $\mathrm{O}^{2-}$ должно 
Таблица 1. Параметры мессбауэровских спектров гексаферритов, легированных титаном

\begin{tabular}{|c|c|c|c|c|c|c|c|}
\hline $\begin{array}{c}\text { Образец } \\
\mathrm{BaFe}_{12-x} \mathrm{Ti}_{x} \mathrm{O}_{19}\end{array}$ & $\begin{array}{c}\text { Компонента } \\
\text { спектра }\end{array}$ & $\begin{array}{c}\text { Изомерный } \\
\text { сдвиг } \delta, \mathrm{mm} / \mathrm{s}\end{array}$ & $\begin{array}{c}\text { Квадрупольное } \\
\text { расщепление } \Delta, \mathrm{mm} / \mathrm{s}\end{array}$ & $\begin{array}{c}\text { Магнитные } \\
\text { поля } H_{\text {eff, }}, \mathrm{kOe}\end{array}$ & $\begin{array}{c}\text { Площади } \\
\text { компонент } S, \% \text { rel. }\end{array}$ & $\begin{array}{c}\text { Ширина } \\
\text { линии } \Gamma, \mathrm{mm} / \mathrm{s}\end{array}$ & $\begin{array}{l}\text { Угол } \\
\theta, \stackrel{\circ}{ }\end{array}$ \\
\hline$x=0$ & $\begin{array}{l}\text { C1-12k }\left(\mathrm{Fe}^{3+}\right)_{\mathrm{VI}} \\
\mathrm{C} 2-4 f_{1}\left(\mathrm{Fe}^{3+}\right)_{\mathrm{IV}} \\
\mathrm{C} 3-4 f_{2}\left(\mathrm{Fe}^{3+}\right)_{\mathrm{VI}} \\
\mathrm{C} 4-2 a\left(\mathrm{Fe}^{3+}\right)_{\mathrm{VI}} \\
\mathrm{C} 5-2 b\left(\mathrm{Fe}^{3+}\right)_{\mathrm{V}}\end{array}$ & $\begin{array}{l}0.35 \\
0.26 \\
0.38 \\
0.34 \\
0.30\end{array}$ & $\begin{array}{l}0.42 \\
0.22 \\
0.20 \\
0.01 \\
2.21\end{array}$ & $\begin{array}{l}414 \\
491 \\
516 \\
507 \\
400\end{array}$ & $\begin{array}{r}50.5 \\
19.8 \\
16.8 \\
7.5 \\
5.3\end{array}$ & $\begin{array}{l}0.32 \\
0.31 \\
0.29 \\
0.26 \\
0.30\end{array}$ & 54.9 \\
\hline$x=0.25$ & $\begin{array}{l}\mathrm{C} 1-12 k\left(\mathrm{Fe}^{3+}\right)_{\mathrm{VI}} \\
\mathrm{C} 2-4 f_{1}\left(\mathrm{Fe}^{3+}\right)_{\mathrm{IV}} \\
\mathrm{C} 3-4 f_{2}\left(\mathrm{Fe}^{3+}\right)_{\mathrm{VI}} \\
\mathrm{C} 4-2 a\left(\mathrm{Fe}^{3+}\right)_{\mathrm{VI}} \\
\mathrm{C} 5-2 b\left(\mathrm{Fe}^{3+}\right)_{\mathrm{V}} \\
\mathrm{C} 6-12 k^{\prime}\left(\mathrm{Fe}^{3+}\right)_{\mathrm{VI}}\end{array}$ & $\begin{array}{l}0.35 \\
0.23 \\
0.36 \\
0.39 \\
0.29 \\
0.42\end{array}$ & $\begin{array}{l}0.40 \\
0.13 \\
0.22 \\
0.17 \\
2.23 \\
0.26\end{array}$ & $\begin{array}{l}412 \\
486 \\
490 \\
510 \\
392 \\
362\end{array}$ & $\begin{array}{r}43.8 \\
21.1 \\
12.3 \\
12.0 \\
3.2 \\
7.6\end{array}$ & $\begin{array}{l}0.39 \\
0.44 \\
0.44 \\
0.38 \\
0.26 \\
0.34\end{array}$ & 55.2 \\
\hline$x=0.50$ & $\begin{array}{l}\mathrm{C} 1-12 k\left(\mathrm{Fe}^{3+}\right)_{\mathrm{VI}} \\
\mathrm{C} 2-4 f_{1}\left(\mathrm{Fe}^{3+}\right)_{\mathrm{IV}} \\
\mathrm{C} 3-2 a\left(\mathrm{Fe}^{3+}\right)_{\mathrm{VI}} \\
\mathrm{C} 4-4 f_{2}\left(\mathrm{Fe}^{3+}\right)_{\mathrm{VI}} \\
\mathrm{C} 5-2 b\left(\mathrm{Fe}^{3+}\right)_{\mathrm{V}} \\
\mathrm{C} 6-12 k^{\prime}\left(\mathrm{Fe}^{3+}\right)_{\mathrm{VI}}\end{array}$ & $\begin{array}{l}0.36 \\
0.26 \\
0.38 \\
0.33 \\
0.22 \\
0.37\end{array}$ & $\begin{array}{l}0.38 \\
0.19 \\
0.18 \\
0.14 \\
2.22 \\
0.31\end{array}$ & $\begin{array}{l}410 \\
472 \\
505 \\
488 \\
387 \\
360\end{array}$ & $\begin{array}{r}40.2 \\
15.4 \\
8.4 \\
19.9 \\
3.5 \\
12.6\end{array}$ & $\begin{array}{l}0.45 \\
0.44 \\
0.31 \\
0.44 \\
0.31 \\
0.61\end{array}$ & 52.0 \\
\hline$x=0.75$ & $\begin{array}{l}\mathrm{C} 1-12 k\left(\mathrm{Fe}^{3+}\right)_{\mathrm{VI}} \\
\mathrm{C} 2-4 f_{1}\left(\mathrm{Fe}^{3+}\right)_{\mathrm{IV}} \\
\mathrm{C} 3-4 f_{2}\left(\mathrm{Fe}^{3+}\right)_{\mathrm{VI}} \\
\mathrm{C} 4-2 a\left(\mathrm{Fe}^{3+}\right)_{\mathrm{VI}} \\
\mathrm{C} 5-2 b\left(\mathrm{Fe}^{3+}\right)_{\mathrm{V}} \\
\mathrm{C} 6-12 k^{\prime}\left(\mathrm{Fe}^{3+}\right)_{\mathrm{VI}} \\
\mathrm{C} 7-12 k^{\prime \prime}\left(\mathrm{Fe}^{3+}\right)_{\mathrm{VI}}\end{array}$ & $\begin{array}{l}0.36 \\
0.26 \\
0.38 \\
0.40 \\
0.30 \\
0.35 \\
0.39\end{array}$ & $\begin{array}{l}0.3 \\
0.09 \\
0.29 \\
0.12 \\
2.17 \\
0.32 \\
0.33\end{array}$ & $\begin{array}{l}409 \\
473 \\
474 \\
497 \\
367 \\
434 \\
358\end{array}$ & $\begin{array}{r}30.8 \\
21.5 \\
12.7 \\
6.4 \\
2.3 \\
7.1 \\
19.2\end{array}$ & $\begin{array}{l}0.47 \\
0.56 \\
0.54 \\
0.34 \\
0.29 \\
0.53 \\
0.77\end{array}$ & 53.5 \\
\hline$x=1.00$ & \begin{tabular}{|l|}
$\mathrm{C} 1-12 k\left(\mathrm{Fe}^{3+}\right)_{\mathrm{VI}}$ \\
$\mathrm{C} 2-4 f_{2}\left(\mathrm{Fe}^{3+}\right)_{\mathrm{VI}}$ \\
$\mathrm{C} 3-4 f_{1}\left(\mathrm{Fe}^{3+}\right)_{\mathrm{IV}}$ \\
$\mathrm{C} 4-2 a\left(\mathrm{Fe}^{3+}\right)_{\mathrm{VI}}$ \\
$\mathrm{C} 5-2 b\left(\mathrm{Fe}^{3+}\right)_{\mathrm{V}}$ \\
$\mathrm{C} 6-12 k^{\prime}\left(\mathrm{Fe}^{3+}\right)_{\mathrm{VI}}$ \\
$\mathrm{C} 7-12 k^{\prime \prime}\left(\mathrm{Fe}^{3+}\right)_{\mathrm{VI}}$ \\
Д- $\left(\mathrm{Fe}^{3+}\right)_{\mathrm{VI}}$
\end{tabular} & $\begin{array}{l}0.36 \\
0.41 \\
0.28 \\
0.35 \\
0.28 \\
0.44 \\
0.41 \\
0.35\end{array}$ & $\begin{array}{l}0.40 \\
0.28 \\
0.19 \\
0.06 \\
1.94 \\
0.48 \\
0.97 \\
0.63\end{array}$ & $\begin{array}{c}408 \\
497 \\
473 \\
498 \\
348 \\
360 \\
319 \\
-\end{array}$ & $\begin{array}{r}32.8 \\
4.3 \\
25.6 \\
11.7 \\
1.1 \\
8.6 \\
2.2 \\
13.7\end{array}$ & $\begin{array}{l}0.52 \\
0.27 \\
0.67 \\
0.58 \\
0.21 \\
0.61 \\
0.24 \\
0.51\end{array}$ & 54.9 \\
\hline$x=1.25$ & $\begin{array}{l}\mathrm{C} 1-12 k\left(\mathrm{Fe}^{3+}\right)_{\mathrm{VI}} \\
\mathrm{C} 2-4 f_{1}\left(\mathrm{Fe}^{3+}\right)_{\mathrm{IV}} \\
\mathrm{C} 3-4 f_{2}\left(\mathrm{Fe}^{3+}\right)_{\mathrm{VI}} \\
\mathrm{C} 4-2 a\left(\mathrm{Fe}^{3+}\right)_{\mathrm{VI}} \\
\mathrm{C} 5-2 b\left(\mathrm{Fe}^{3+}\right)_{\mathrm{V}} \\
\mathrm{C} 6-12 k^{\prime}\left(\mathrm{Fe}^{3+}\right)_{\mathrm{VI}} \\
\mathrm{C} 7-12 k^{\prime \prime}\left(\mathrm{Fe}^{3+}\right)_{\mathrm{VI}} \\
C 8-\alpha-\mathrm{Fe}_{2} \mathrm{O}_{3} \\
Д-\left(\mathrm{Fe}^{3+}\right)_{\mathrm{VI}}\end{array}$ & $\begin{array}{l}0.36 \\
0.28 \\
0.39 \\
0.33 \\
0.23 \\
0.50 \\
0.56 \\
0.37 \\
0.35\end{array}$ & $\begin{array}{r}0.40 \\
0.20 \\
0.25 \\
0.13 \\
2.07 \\
0.72 \\
0.77 \\
-0.23 \\
0.66 \\
\end{array}$ & $\begin{array}{c}409 \\
470 \\
503 \\
491 \\
387 \\
375 \\
323 \\
515 \\
-\end{array}$ & $\begin{array}{r}29.4 \\
17.1 \\
7.3 \\
9.3 \\
1.2 \\
2.5 \\
5.1 \\
3.3 \\
24.9\end{array}$ & $\begin{array}{l}0.53 \\
0.60 \\
0.53 \\
0.40 \\
0.21 \\
0.27 \\
0.56 \\
0.21 \\
0.48\end{array}$ & 53.8 \\
\hline$x=1.50$ & $\begin{array}{l}\mathrm{C} 1-12 k\left(\mathrm{Fe}^{3+}\right)_{\mathrm{VI}} \\
\mathrm{C} 2-4 f_{1}\left(\mathrm{Fe}^{3+}\right)_{\mathrm{IV}} \\
\mathrm{C} 3-4 f_{2}\left(\mathrm{Fe}^{3+}\right)_{\mathrm{VI}} \\
\mathrm{C} 4-2 a\left(\mathrm{Fe}^{3+}\right)_{\mathrm{VI}} \\
\mathrm{C} 5-2 b\left(\mathrm{Fe}^{3+}\right)_{\mathrm{V}} \\
\mathrm{C} 6-12 k^{\prime}\left(\mathrm{Fe}^{3+}\right)_{\mathrm{VI}} \\
\mathrm{C} 7-12 k^{\prime \prime}\left(\mathrm{Fe}^{3+}\right)_{\mathrm{VI}} \\
\mathrm{C} 8-\alpha-\mathrm{Fe}_{2} \mathrm{O}_{3} \\
\left.\text { Д-(Fe } \mathrm{Fe}^{3+}\right)_{\mathrm{VI}}\end{array}$ & $\begin{array}{l}0.36 \\
0.28 \\
0.35 \\
0.30 \\
0.28 \\
0.43 \\
0.65 \\
0.38 \\
0.39\end{array}$ & $\begin{array}{r}0.39 \\
0.12 \\
0.26 \\
-0.10 \\
2.15 \\
0.56 \\
0.65 \\
-0.17 \\
0.67\end{array}$ & $\begin{array}{c}409 \\
471 \\
492 \\
489 \\
395 \\
374 \\
327 \\
517 \\
-\end{array}$ & $\begin{array}{r}24.7 \\
9.8 \\
13.7 \\
2.9 \\
1.3 \\
4.9 \\
2.8 \\
6.2 \\
33.7\end{array}$ & $\begin{array}{l}0.58 \\
0.58 \\
0.58 \\
0.22 \\
0.21 \\
0.58 \\
0.37 \\
0.31 \\
0.51\end{array}$ & 55.5 \\
\hline
\end{tabular}



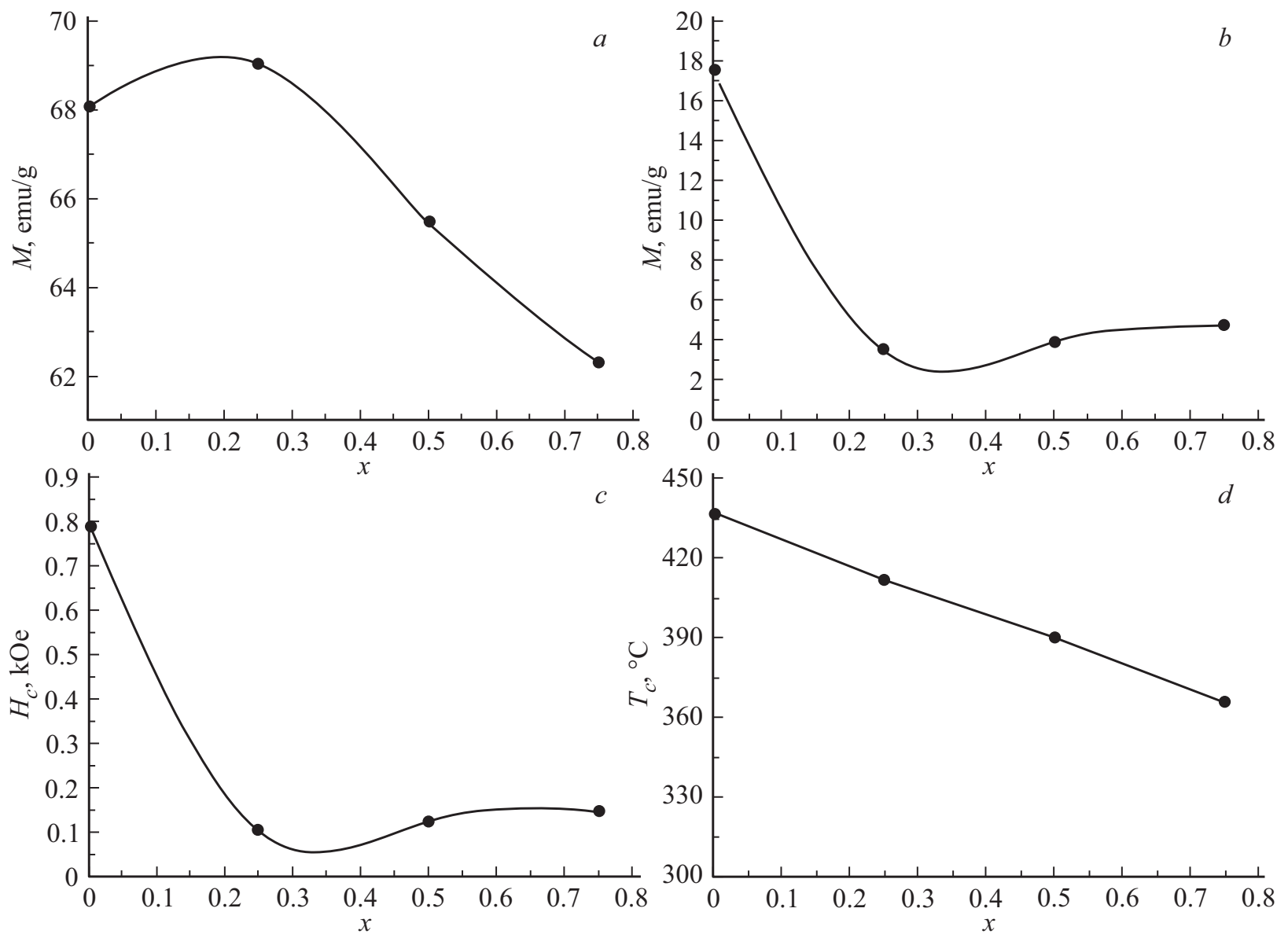

Рис. 2. Зависимости магнитных характеристик $\mathrm{BaFe}_{12-x} \mathrm{Ti}_{x} \mathrm{O}_{19}$ от $x: a-$ удельной намагниченности $M_{s}$, emu/g; $b-$ коэрцитивной силы $H_{c}, \mathrm{kOe} ; c$ - остаточной намагничености $M_{r}, \mathrm{emu} / \mathrm{g} ; d-$ температуры Кюри $T_{c},{ }^{\circ} \mathrm{C}$.

быть в пределах $0.94 \pm 0.02 \mathrm{~mm} / \mathrm{s}$ для тетраэдрических позиций и $1.14 \pm 0.02 \mathrm{~mm} / \mathrm{s}$ для октаэдрических позиций. Однако, если предположить, что в шпинельном блоке гексаферрита в октаэдрах $12 k$ происходит электронный обмен $\mathrm{Fe}^{3+} \rightarrow \mathrm{Fe}^{2+}$, как в магнетите установленный в работе [24], то изомерный сдвиг для ионов Fе октаэдрических позиций магнетита в мессбауэровских спектрах должен быть $0.67 \mathrm{~mm} / \mathrm{s}$, что установлено в многочисленных исследованиях магнетита. В образце с $x=1.5$ изомерный сдвиг ионов $\mathrm{Fe}^{3+} 0.65 \mathrm{~mm} / \mathrm{s}$, что довольно близко к $0.67 \mathrm{~mm} / \mathrm{s}$, как в незамещенном магнетите при электронном обмене. Из этого можно сделать вывод, что при малых замещениях $\mathrm{Fe}^{3+}$ ионами $\mathrm{Ti}^{4+}$ в шпинельном блоке гексаферрита происходит лишь частичный электронный обмен с увеличением электронной плотности $3 d$-электронов, в то время как при $x>1.0$ реализуется механизм электронного обмена $\mathrm{Fe}^{3+} \leftrightarrow \mathrm{Fe}^{2+}$, подобный происходящему в магнетите. Довольно близкое совпадение изомерного сдвига в дополнительных секстетах при $x=1.5$ с наблюдаемым в магнетите для октаэдрических позиций, указывает на большую вероятность объяснения увеличения изомерного сдвига наличием электронного обмена в $12 k$-позиции гексаферрита, нежели модель повышения ионной связи, которая не может обеспечить наблюдаемого повышения изомерного сдвига в дополнительных секстетах мессбауэровского спектра.

В отличие от магнетита, где при электронном обмене $\Delta$ ионов $\mathrm{Fe}$ равно 0 , за счет высокой симметричности октаэдра, в гексаферрите $\mathrm{BaFe}_{12-x} \mathrm{Ti}_{x} \mathrm{O}_{19}$, в результате образования дефектной структуры, локальные искажения октаэдра довольно высоки и $\Delta$ достигает до $0.5 \mathrm{~mm} / \mathrm{s}$, что не связано с происходящим электронным обменом.

Магнитные поля на ядрах $\mathrm{Fe}^{57}$ монотонно уменьшаются с ростом $x$. Сопоставляя площади секстетов, можно отметить некоторое отклонение площадей в тетраэдрических позициях и бипирамиде от теоретических значений (см. табл. 1). Это можно объяснить различием амплитуды колебаний ионов $\mathrm{Fe}$ в этих полиэдрах. Меньшая амплитуда колебаний ионов $\mathrm{Fe}$ в тетраэдрах по сравнению с октаэдрами увеличивает величину резонансного эффекта и, соответственно, площадь от этих ионов, а большая амплитуда колебаний ионов $\mathrm{Fe}$ в бипирамиде в одном из направлений, уменьшает величину резонансного эффекта.

Сопоставление угла $\theta$ образцов $\mathrm{BaFe}_{12-x} \mathrm{Ti}_{x} \mathrm{O}_{19}$ с $x$ подтверждает, что все образцы практически являются изотропными. 

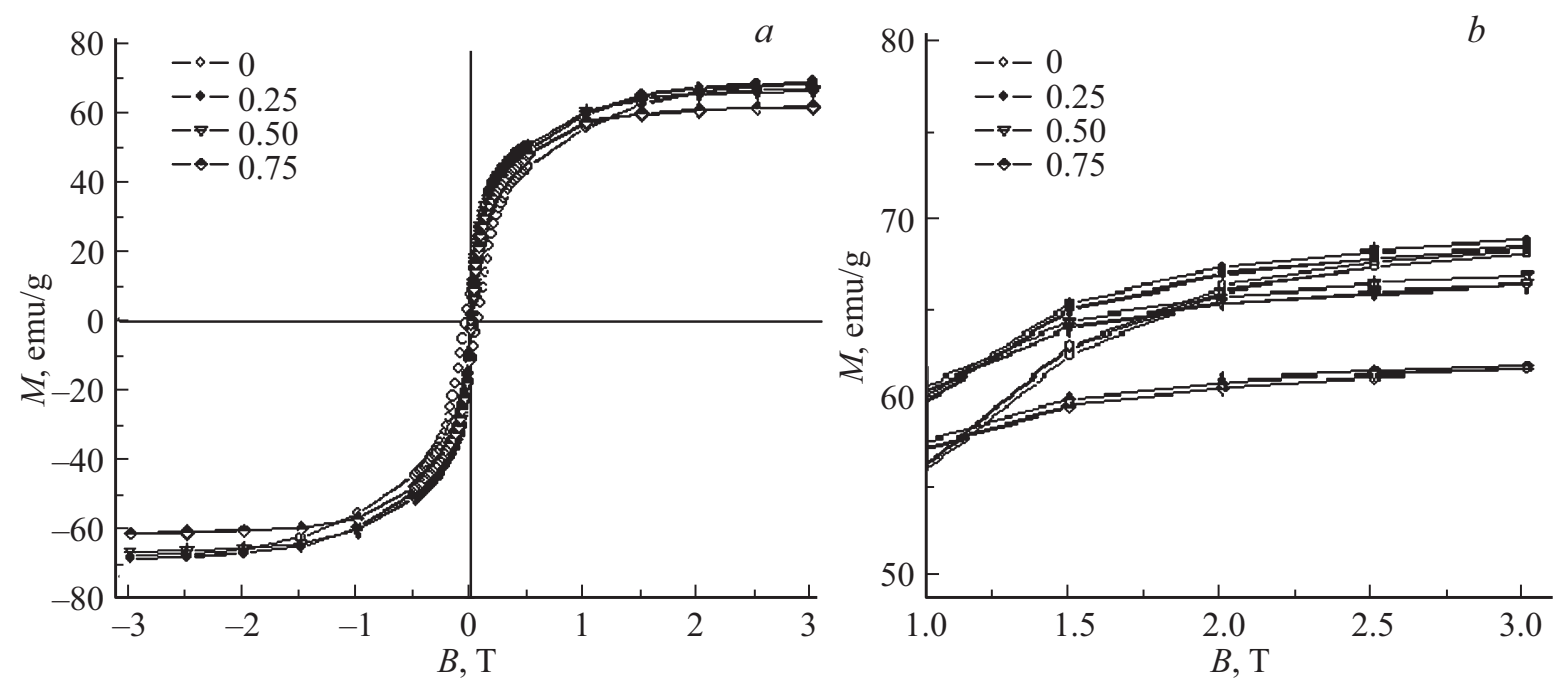

Рис. 3. Петли гистерезиса гексаферрита $\mathrm{BaFe}_{12-x} \mathrm{Ti}_{x} \mathrm{O}_{19}(a)$, в увеличенном масштабе участок с $B=1-3(b)$.
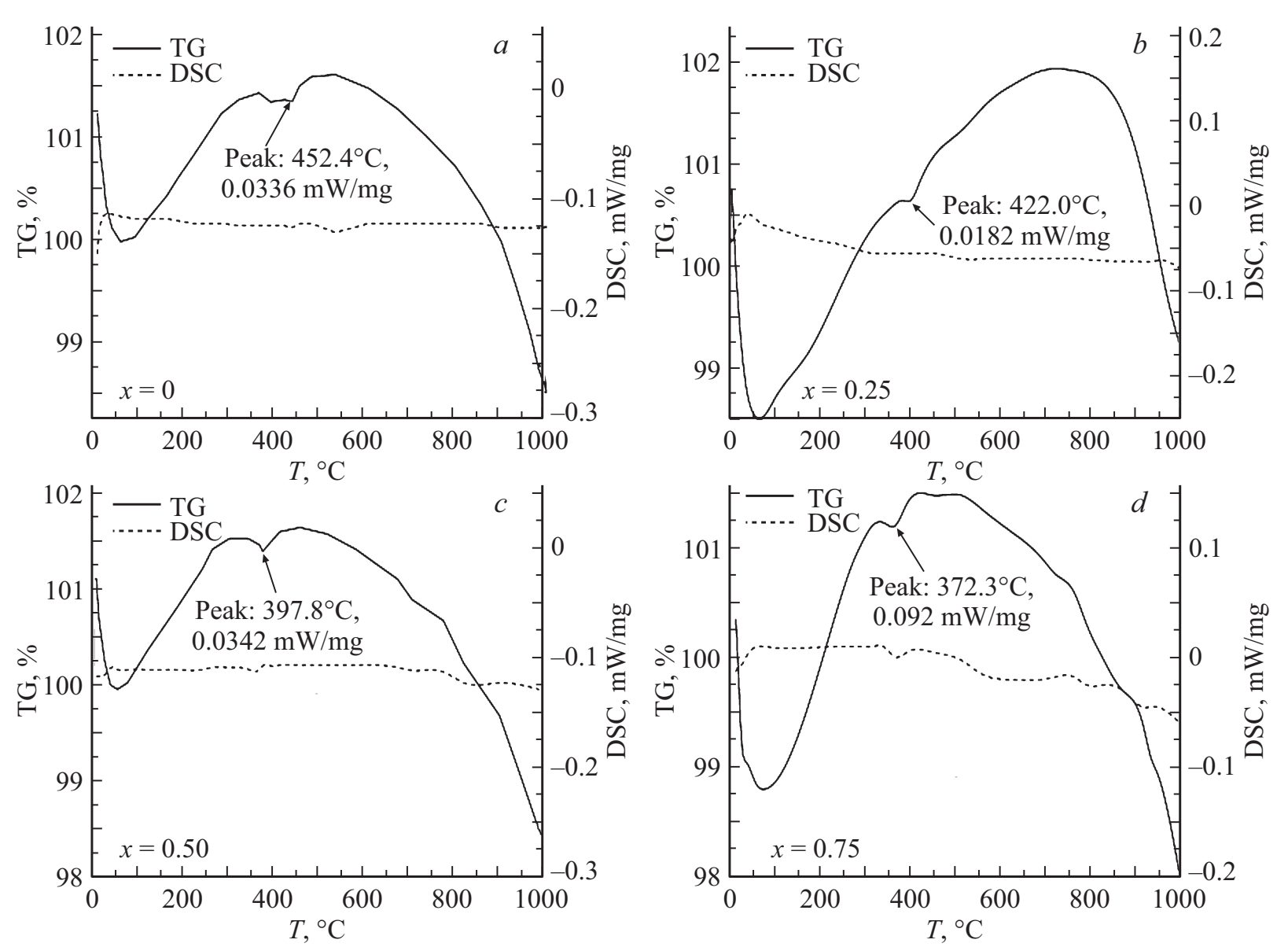

Рис. 4. Графики дифференциальной сканирующей калометрии (DSC) и потери массы (TG) гексаферритов $\mathrm{BaFe}_{12-x} \mathrm{Ti}_{x} \mathrm{O}_{19}(x=0.0$; $0.25 ; 0.50 ; 0.75)$.

Измеренные магнитные характеристики исследованных образцов в диапазоне $x$ от 0 до 0.75 удельной намагниченности $M$, остаточной намагниченности $M_{r}$, коэрцитивной силы $H_{c}$ и температуры Кюри $T_{c}$ в виде графиков от степени замещения $x$ приведены на рис. 2 .
Удельная намагниченность (рис. 2, $a$ ), увеличивается от $68 \mathrm{emu} / \mathrm{g}$ незамещенного гексаферрита до $69 \mathrm{emu} / \mathrm{g}$ при $x=0.25$, а затем монотонно уменьшается до $62 \mathrm{emu} / \mathrm{g}$ при $x=0.75$. Это объясняется тем, что на первоначальном этапе замещение происходит преимущественно 

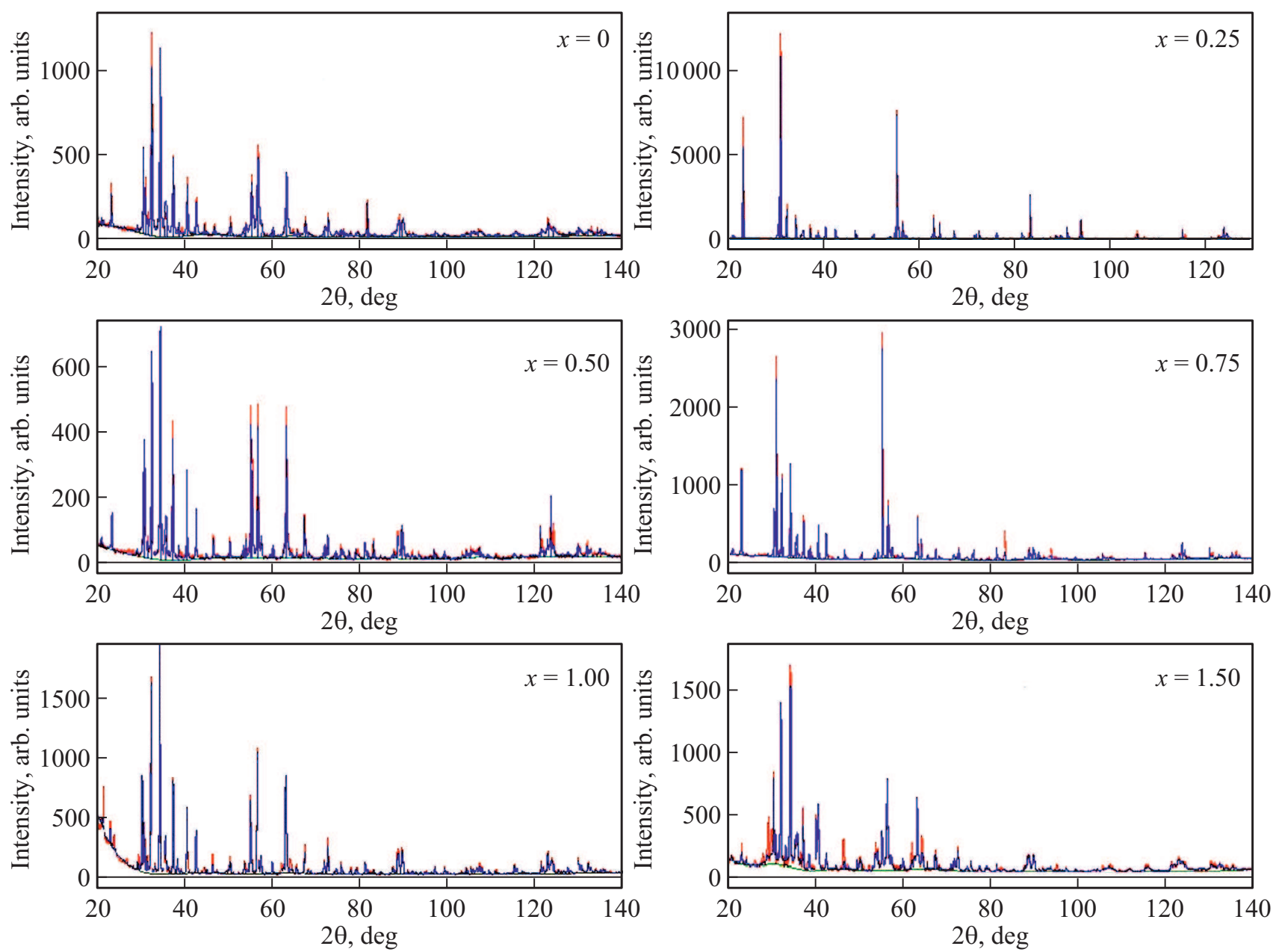

Рис. 5. Рентгенораммы гексаферритов $\mathrm{BaFe}_{12-x} \mathrm{Ti}_{x} \mathrm{O}_{19}(x=0.0 ; 0.25 ; 0.50 ; 0.75 ; 1.00 ; 1.50)$.

в позиции $4 f_{2}$, увеличивая при этом результирующий магнитный момент, а затем преобладают замещения в $12 k$ и $2 b$ (см. табл. 1 ), которые уменьшают результирующий магнитный момент и, соответственно, удельную намагниченность, что соответствует данным [17]. Коэрцитивная сила и остаточная намагниченность ведут себя одинаково, уменьшаясь от значений незамещенного гексаферрита до значений при $x=0.25$, а затем они практически неизменны до $x=0.75$. Температура Кюри, измеренная с помощью синхронного термического анализа гексаферритов в магнитном поле (рис. 2,d) показала убывающую линейную зависимость.

Полевые зависимости намагниченности (рис. 3,a) и фрагменты в увеличенном масштабе (рис. $3, b$ ) для незамещенного гексаферрита и составов с $x$ до 0.75 показали некоторое их различие. Можно отметить, что в измеренном диапазоне $B(T)$ не наступило полного насыщения намагниченности, видно разбиение петель гистерезиса на две группы: петли с более высокими значениями удельной намагниченности $(x=0,0.25,0.5)$ и с меньшей $(x=0.75)$. Кроме того, наибольшую прямоугольность петели гистерезиса имеет образец с $x=0.25$, что согласуется с пиком намагниченности (рис. $2, a)$.
C помощью синхронного термического анализа быди измерены тепловые хараетристики образцов состава $x=0-0.75$, полученные при этом зависимости дифференциальной сканирующей калометрии (ДСК) и потери массы (ТГ) в магнитном поле, приведены на рис. 4. На всех кривых ДСК отмечаются эндотермические эффекты, связанные с переходом состояния образцов из магнитоупрядоченного феримагнитного состояния в параманитное, причем температура перехода понижается стого линейно от $452.4^{\circ} \mathrm{C}$ до $371.3^{\circ} \mathrm{C}$. Такую же зависимость отражает и график ТГ, полученный при измерении образца в магнитном поле (рис. 2, $d$ ). При этом при переходе магнитоупорядоченного образца при температуре Кюри на зависимости ТГ от температуры появляется скачек сигнала, по которому можно определять температуру перехода. Для сравнения влияния магнитного поля на сигнал ТГ, образец с $x=0.25$ был снят без наложения такового, где сигнал перехода на ТГ отсутствует. Графически сигнал на ТГ менее размыт, нежели эндотермический пик, поэтому определение температуры Кюри в этом случае является более точным.

По рентгеновским дифрактограммам (рис. 5) был определен фазовый состав образцов с $x=0-0.75,1.25$ 
Таблица 2. Параметры элементарной ячейки $\mathrm{BaFe}_{12-x} \mathrm{Ti}_{x} \mathrm{O}_{19}$ и фазовый состав образцов

\begin{tabular}{|c|c|c|c|c|c|}
\hline \multirow{2}{*}{$\begin{array}{c}\text { Образец } \\
\mathrm{BaFe}_{12-x} \mathrm{Ti}_{x} \mathrm{O}_{19}\end{array}$} & \multicolumn{4}{|c|}{ Параметры элементарной ячейки гексаферрита } & \multirow{2}{*}{ Фазовый состав, \% } \\
\hline & $a, \AA$ & $b, \AA$ & $c, \AA$ & $V, \AA$ & \\
\hline$x=0$ & $5.8941(9)$ & $5.8941(9)$ & $23.202(4)$ & $698.06(18)$ & $\mathrm{BaFe}_{12} \mathrm{O}_{19}-100$ \\
\hline$x=0.25$ & $5.8870(9)$ & & $23.1734(13)$ & $695.52(16)$ & $\mathrm{BaFe}_{11.75} \mathrm{Ti}_{0.25} \mathrm{O}_{19}-100$ \\
\hline $\begin{array}{l}x=0.50 \\
x=0.75 \\
x=1.0\end{array}$ & $\begin{array}{l}5.888(3) \\
5.870(4) \\
5.8858(4)\end{array}$ & & $\begin{array}{l}23.225(15) \\
23.2447(12) \\
23.2307(18)\end{array}$ & $\begin{array}{l}697.41(7) \\
697.66(8) \\
699.93(9)\end{array}$ & $\begin{array}{l}\mathrm{BaFe}_{11.5} \mathrm{Ti}_{0.5} \mathrm{O}_{19}-100 \\
\mathrm{BaFe}_{11.25} \mathrm{Ti}_{0.75} \mathrm{O}_{19}-100 \\
\mathrm{BaFe}_{11.25} \mathrm{Ti}_{0.75} \mathrm{O}_{19}-95.1, \\
\mathrm{Fe}_{2} \mathrm{TiO}_{4}-2, \mathrm{FeTiO}_{3}-2.5\end{array}$ \\
\hline$x=1.25$ & $5.8886(6)$ & & $23.232(2)$ & $697.65(12)$ & $\begin{array}{l}\mathrm{BaFe}_{11.25} \mathrm{Ti}_{0.75} \mathrm{O}_{19}-81 \\
\mathrm{Fe}_{3} \mathrm{O}_{4}-12, \mathrm{TiO}_{2}-7.2\end{array}$ \\
\hline$x=1.50$ & $5.886(8)$ & & $23.219(11)$ & $696.65(17)$ & $\begin{array}{l}\mathrm{BaFe}_{11.25} \mathrm{Ti}_{0.75} \mathrm{O}_{19}-70.2, \\
\mathrm{Fe}_{3} \mathrm{O}_{4}-5.2, \mathrm{FeTiO}_{3}-2.9, \\
\mathrm{Ti}_{2} \mathrm{O}_{4}-9,4, \mathrm{TiO}_{2}-14.7 \\
\mathrm{Ti}_{2} \mathrm{O}_{3}-0.5\end{array}$ \\
\hline
\end{tabular}

и 1.5 , а рассчитанные по межплоскостным расстояниям параметры элементарной ячейки гексаферритов приведены в табл. 2.

Из табл. 2 видим, что в диапазоне состава с $x$ от 0 до 0.75 включительно, образцы представляют собой монофракцию $\mathrm{BaFe}_{12-x} \mathrm{Ti}_{x} \mathrm{O}_{19}$. Из этого следует, что в пределах этого диапазона титан входит изоморфно в решетку гексаферрита. Начиная с $x=1.0$, данные рентгенографии устанавливают появление различных железотитановых соединений (табл. 2) при практически постоянном составе гексаферрита $\mathrm{BaFe}_{11.25} \mathrm{Ti}_{0.75} \mathrm{O}_{19}$. Это свидетельствует об ограниченном изоморфизме гексаферрита и пределе изоморфизма в диапазоне $0.75<x<1.0$, что согласуется с данными мессбауэровской спектроскопии, показывающими отсутствие дублета в спектрах образцов с $x=0.75$ и появление дублета при $x=1.0$.

Рассчитанные параметры элементарной ячейки $\mathrm{BaFe}_{12-x} \mathrm{Ti}_{x} \mathrm{O}_{19}$ (табл. 2) показывают, что вхождение титана в решетку понижает параметр $a$ в составе с $x=0.25$ относительно незамещенного гексаферрита, но дальнейшее увеличение $x$ не влияет на этот параметр. В отличие от параметра $a$, параметр $c$ и объем $V$ элементарной ячейки показывают максимумы в диапазоне 0.75-1.0, что также можно связать с достижением предела изоморфизма.

\section{4. Заключение}

В результате проведенных иследований гексаферрита бария легированного титаном было показано, что в гексагональном феррите бария легированого титаном осуществляется ограниченный гетеровалентный изоморфизм по схеме $2 \mathrm{Fe}^{3+} \rightarrow \mathrm{Ti}^{4+}+\mathrm{Fe}^{2+}$. Установлено, что предел гетеровалентного изоморфного замещения в $\mathrm{BaFe}_{12-x} \mathrm{Ti}_{x} \mathrm{O}_{19}$ лежит в диапазоне значений $0.75<x<1.0$, далее титан в соединении с железом, выделенным из позиций $12 k$, и $2 b$, образует парамагнитную ульвешпинель, магнетит и диоксид титана по данным рентгенографии и мессбауэровской спектроскопии. В образцах с $x=1.25$ и 1.5 установлен оксид железа $\alpha$ - $\mathrm{Fe}_{2} \mathrm{O}_{3}$ по мессбауэровским параметрам. Образование железотитановых соединений и диоксида титана фиксируется при $x=1.0$, а их содержание увеличивается по мере возрастания $x$. Обнаружен электронный обмен $\mathrm{Fe}^{3+} \leftrightarrow \mathrm{Fe}^{2+}$ в диапазоне $x=1.0-1.5$ в шпинельном блоке структуры $\mathrm{BaFe}_{12-x} \mathrm{Ti}_{x} \mathrm{O}_{19}$, диагностированный по величине изомерного сдвига, аналогичного наблюдаемому в магнетите. Дополнительные секстеты в мессбауэровских спектрах гексаферрита бария могут образовываться при локализации ионов $\mathrm{Ti}^{4+}$ преимущественно в позициях $12 k$ и $2 b$, за счет оборванных обменных связей $\mathrm{Fe}(12 k)-\mathrm{O}-\mathrm{Fe}(12 k), \mathrm{Fe}\left(4 f_{2}\right)-\mathrm{O}-\mathrm{Fe}(12 k)$, $\mathrm{Fe}(2 a)-\mathrm{O}-\mathrm{Fe}(12 k)$, а также $\mathrm{Fe}\left(4 f_{2}\right)-\mathrm{O}-\mathrm{Fe}(2 b)$, обозначенные как $12 k^{\prime}$ и $12 k^{\prime \prime}$.

Зависимость удельной намагниченности $\mathrm{BaFe}_{12-x} \mathrm{Ti}_{x} \mathrm{O}_{19}$ показала, что на ней имеется максимум при $x=0.25$, вследствие преобладания при этом замещения в позиции $4 f_{2}$, после чего намагниченность монотонно уменьшается с увеличением $x$.

Проведенные исследования показывают пределы использования легированного титаном гексаферрита бария, а также возможность получения образцов с наперед заданными магнитными свойствами для промышленного использования.

\section{Финансирование работы}

Исследования выполнены при поддержке Российского научного фонда (соглашение № 19-19-00694 от 06 мая 2019).

\section{Конфликт интересов}

Авторы заявляют, что у них нет конфликта интересов. 


\section{Список литературы}

[1] V. Adelskold. Arkiv Mineralogi Geologi A 12, 1 (1938).

[2] R.C. Pullar. Prog. Mater. Sci., 57, 1191 (2012).

[3] Я. Смит, Х. Вейн. Ферриты. ИЛ, М. (1962). 504 с.

[4] В.В. Коровушкин, М.Н. Шипко, В.Г. Костишин, И.М. Исаев, А.Ю. Миронович, С.В. Труханов, А.В. Труханов. Неорган. материалы 55, 10, 1065 (2019).

[5] А.С. Камзин, Л.П. Ольховик. ФТТ 41, 10, 1806 (1999).

[6] В.В. Коровушкин, А.В. Труханов, М.Н. Шипко, В.Г. Костишин, И.М. Исаев, А.Ю. Миронович, С.В. Труханов. Журн. неорган. химии 64, 5, 463 (2019).

[7] А.В. Труханов, В.Г. Костишин, В.В. Коровушкин, Л.В. Панина, С.В. Труханов, В.А. Турченко, И.С. Поляков, Р.Х. Рахматулин, Г.А. Филатов, Т.И. Зубарь, В.В. Олейник, Е.С. Яковенко, Л.Ю. Мацуй, Л.Л. Вовченко, В.Л. Лаунец, Е.Л. Руханова. ФТТ 60, 9, 1723 (2018).

[8] Ш.Ш. Башкиров, А.В. Либерман, А.А. Валиулин, Л.Д. Зарипова, С.В. Кокин. ФТТ 42, 1, 76 (2000).

[9] T. Tsutaoka, A. Tsurunaga, N. Koga. J. Magn. Magn. Mater. 399, 64 (2016).

[10] M.H. Shams, A. Rozatian, M. Yousefi, J. Valıček, V. Šepelák. J. Magn. Magn. Mater. 399, 10 (2016).

[11] V.V. Somana, V.M. Nanotib, D.K. Kulkarnic, V.V. Somand. Phys. Proc. 54, 30 (2014).

[12] A. Ghasemi, A. Hossienpour, A. Morisako, A. Saatchi, M. Salehi. J. Magn. Magn. Mater. 302, 429 (2006).

[13] R. Alam, M. Tehrani, M. Moradi, E. Hosseinpour, A. Sharbati. J. Magn. Magn. Mater. 323, 1040 (2011).

[14] Y. Zheng, Z. Yu, Y. Shao, S. Mo, Y. Lin. Hyperfine Interact. 94, 2035 (1994).

[15] R. Alam, M. Moradi, H. Nikmanesh, J. Ventura, M. Rostami. J. Magn. Magn. Mater. 402, 20 (2016).

[16] C.L. Lengauer, E. Tillmans, G. Hentschel. Mineral. Petrol. 71, 1 (2001).

[17] P.A. Mariño-Castellanos, J. Anglada-Rivera, A. Cruz-Fuentes, R. Lora-Serrano. J. Magn. Magn. Mater. 280, 3, 214 (2004).

[18] P. Quoiroz, B. Halbedel, A. Bustamante, J. Gonzalez. Hyperfine Interact. 202, 1, 97 (2011).

[19] D.A. Vinnik, D.A. Zherebtsov, L.S. Mashkovtseva, A.S. Semisalova, I.V. Krivtsov, L.I. Isaenko, G.G. Mikhailov, R. Niewa. Cryst. Growth Design 14, 11, 5834 (2014).

[20] D.A. Vinnik, D.A. Zherebtsov, L.S. Mashkovtseva, N.S. Perov, A.S. Semisalova, I.V. Krivtsov, L.I. Isaenko, G.G. Mikhailov. $6^{\text {th }}$ Baikal Int. Conf. 161 (2014).

[21] F. Menil. J. Phys. Chem. Solids 46, 7, 763 (1985).

[22] R. Ingalls. Phys. Rev. A 133, 787 (1964).

[23] Г. Бенкрофт, Р. Меддок, Р. Барнс. Физика минералов. Мир, M. (1971). C. 179-204.

[24] E.J.W. Verwey, P.H. Haaman. Physica 8, 979 (1941).

Редактор Т.Н. Василевская 